against cancer". Yet it is less than ten years since President Richard M. Nixon and Senator Edward M. Kennedy were vying with each other to devise still more generous programmes for cancer research. Over the years, the National Cancer Institute, a constituent of the National Institutes of Health, has been the centre of most of this attention, with the result that its operating budget now exceeds $\$ 1,000$ million a year. But something has gone wrong. Now hardly a week seems to pass without the director of the institute, Dr Vincent T. DeVita, appearing before one investigative committee or another to defend his institution against some fresh set of allegations. What can be the explanation? Has Congress fallen out of love with the war against cancer, or is there a more sinister explanation?

Part of the trouble is that Dr DeVita is new to the job - he took up his post only at the beginning of the year - and better known as a scientist than as a politician. Indeed, it seems that he has concentrated in the past few months on bringing a sense of direction to the research programme that he is paid to direct. This part of his job seems to have been done with such flair that when, earlier this year, Senator Hatch's committee sought to saddle him with responsibility for the earlier maladministration of research grants, a group of Dr DeVita's colleagues wrote expressing their admiration for their new director. Nobody would be surprised, however, if in the course of spending more than \$20 million a week on research, Dr DeVita has neglected to pay court as assiduously as he might to those who hold the purse strings in Congress. Or is it that Congress, like the National Institutes of Health, is waiting to see if the new director will turn out to be a political appointment, the Administration's representative within the institutes and not the institutes' means of interceding both with the Administration and with Congress? It goes without saying that a political appointment, a sharp break with precedent, could be disastrous for the National Institutes of Health, whose most urgent collective need is coherence and not further partition.

Dr DeVita's problems are nevertheless substantial. Accusations earlier in the year that some research grants had been used and administered in such a way that data of doubtful value had been gathered appear to have been substantiated. Neither then nor since, however, has Congress asked itself whether such incidents, acknowledged to be rare, can be avoided in such a gigantic programme for throwing money at the problem of cancer. Much of the same is true of last week's hearing in the House of Representatives, when Dr DeVita was required to deal with newspaper allegations that cancer patients treated with novel drugs within the framework of agreed experimental protocols had died as a result of the drugs rather than of the diseases the drugs might, with luck, have treated. How else, it might be asked, can novel drugs be tried in human beings? This week, Senator Paula Hawkins will return to the same charge; she has been asking, ever since she reached the Senate in January, why, a decade after the war against cancer was conceived of, people still die of all but a few forms of the disease. It is to be hoped that Dr DeVita and his colleagues will have the courage to tell Senator Hawkins the truth. The war against cancer was misconceived. The idea that such a problem might be made to go away by spending money was always destined to end in disillusion. From the start, it has been plain that while even successful methods of treatment lack a sufficient basis of understanding, they cannot be generalized. Yet, it must also be made clear, developments in the past few years promise substantial steps in the right direction, whatever that may be.

The practical consequences of such a confession on the part of the National Cancer Institute need not be as disastrous as they might seem. Congress may (separately from this week's proceedings) reduce the budget earmarked for the institute. It may have no choice. But the cancer institute would be more easily managed, and would be more effective, if it were forced to be more discriminating, at its very generous margin, in how its funds are spent. And the enterprise that it represents would be much less vulnerable than at present to the constant sniping that now afflicts it if both Congress and the United States public understood more clearly that they must be patient.

\section{Shame on New York}

\author{
Baseball has become a game of chance. \\ How should it be reformed?
}

The city of New York has had a bad week. The leading article in last Thursday's New York Times was understandably entitled "The shape of New York's shame". Oddly, however, the newspaper was castigating the city council for a piece of flagrant but routine gerrymandering with the city's electoral boundaries, incurring as a result a reproof from the courts. But last Thursday morning, the shame hanging over the city was the humiliating defeat the previous evening of the city's most prosperous baseball team, the New York Yankees. In the process, the Yankees also lost the best-of-seven competition between North American baseball teams quaintly known as the "World Series". Last week's defeat was all the more galling because the Yankees were soundly beaten by the Los Angeles Dodgers, within living memory resident in Brooklyn and much resented for their defection. This gloom is yet another proof that something must be done to reform spectator sports in which the object is to hit a ball with some solid object, in baseball called a "bat".

At least to a first approximation, the interaction of a baseball and a bat is a soluble two-body problem. The bat in baseball is a simple object, cylindrically symmetrical about an axis, while the complication arising because some ball-throwers (called "pitchers") claim to be able to throw "curve-balls" is irrelevant to last week's disasters because both teams appear to have been incapable of hitting them. Moreover, since baseball of ficials have taken to measuring the speed with which individual baseballs are delivered, there is a wealth of empirical data on which a proper mechanics of baseball might be founded. Speeds of up to 40 metres per second are recorded.

The difficulty of baseball is, first, that of hitting the ball and, second, that of knowing where it will go when hit: good players appear to be able to hit one fair ball in three, but usually even the best players appear at a loss to know whether the ball will shoot high in the air (in which case it may be caught and they will be dismissed), vertically downwards into the ground or upwards and backwards, into the crowd. Only occasionally, perhaps half a dozen times in several hours, does the ball perform as every batter hopes, carrying over the boundary fence for a home run. Thus, it appears, baseball has become an elaborate game of chance. In this year's World Series, there seems to have been very little to choose between the batting performance of the two teams. Part of the reason why the Yankees lost is that they were not as skilled at catching and throwing the ball as were the Dodgers. It is now a matter of great importance to devise some way of ridding baseball of the luck on which it now depends, and which is a simple consequence of the circular cross-section of the baseball bat. Is there a place in baseball for the cricket bat?

Even New Yorkers will, however, agree that the most serious cause of the Yankees' defeat was the evil chance that attended one of the crucial decisions by the team's manager, $\mathrm{Mr}$ Robert Lemon. The issue is complicated by the requirements of this year's rules for the World Series that the pitcher, the man who throws the ball for his team, should also take his turn with the bat. At a point half-way through last Wednesday's game, Mr Lemon exercised his right to replace his successful pitcher due to bat with somebody reputed to be more skilled at hitting the ball, but who promptly failed to do so. Yet if the gamble had succeeded, the Yankees would have gained three runs and the Dodgers would have been too demoralized to sustain the struggle. What will happen now to Mr Lemon, who works for an owner so hottempered that he had to watch Wednesday's game with his hand in a cast after a fist-fight in a Los Angeles elevator, remains to be seen. Wisely, he has been keeping his own counsel. But is it not demeaning, and intolerable, that grown men's careers and the temper of a great city should be determined by the apparently random trajectories produced by trying to hit a baseball with a cylindrically symmetrical bat? 